\title{
Illiteracy Effects on Local Development in the Moroccan Rural World: Challenges and Recommendations
}

\author{
Correspondence: $\quad$ Bachiri Housseine Assistant Professor, Faculty of Sciences and Technologies (FSTT), \\ <Housseinebachiri87@gmail.com> Abdelmalek Essaâdi University, Tangier-Morocco.
}

\begin{abstract}
This paper fundamentally aspires to make context-based recommendations to the increasingly rising number of Moroccan female cooperatives in rural areas, particularly in the region of Fes-Meknes. Similarly, it endeavors to problematize illiteracy and its effects on local and regional development among rural women in the aforementioned region. It must be noted that solidarity cooperatives unquestionably help mitigate both feminine poverty and unemployment, and simultaneously incrementally establish an ongoing entrepreneurial platform for rural women. Such a platform can directly grant the potentiality of helping these women make quantum leaps in development, as well as become socio-culturally emancipated from the stereotypes and clichés that have kept them invisible for decades in the so-called domestic sphere. The data gathered by means of focus groups' sessions in different Fes-Meknes areas and villages, Ifrane, Azrou, Imouzzer, Sefrou and Ain Louh, was of paramount importance in making recommendations that are realistically inspired and meticulously drawn from research informants whose participation in local and regional development, albeit challenges, has drawn a significant amount of attention from state actors, such as the Office of Development and Cooperation (ODCO) and associations of civil society, such as the Moroccan Center for Innovation and Social Entrepreneurship (MCISE). One can confidently state that human development can solely be born out of solidarity, collaboration and encouragement in order to ultimately defy social ills and create seamless cohesion and prosperity.
\end{abstract}

Keywords: Rural women, Feminine poverty, Social and solidarity economy, Inclusion, Illiteracy

\section{Introduction}

In recent years, Social and Solidarity Economy (SSE) has unequivocally become one of the most momentous vehicles for achieving economic development and social stability in a myriad of developing and developed economies due to its contribution to GDP growth, as well as wealth and job creation. Additionally, SSE plays a vital role in enhancing social inclusion, especially the most marginalized, by providing a sustainable access to labor market alongside education, health and housing.

It must be noted that exclusion, intentional or unintentional, from the labor market exposes individuals to extreme poverty, mediocre quality of life and low self-esteem. The active participation of marginalized people in social economy organizations (as employees, but ideally as business owners) is a major step in combating social exclusion and attaining an adequate standard of living. Needless to say, social cohesion is pivotal, for inclusion and exclusion are fundamental for communities' development and well-being (Gough \& Olofsson, 1999; Vertovec, 2003; Reitz et al., 2009; Bruhn, 2009; Jenson, 2010; Hickman et al., 2012; Larsen, 2013; Dobbernack, 2014; Dragolov et al., 2016; Mizukami, 2016).

In this regard, Maxwell comes up with a first working definition of social cohesion for the Canadian Policy Research Networks:

Social cohesion involves building shared values and communities of interpretation, reducing disparities in wealth and income, and generally enabling people to have a sense that they are engaged in a common enterprise, facing shared challenges, and that they are members of the same community (Maxwell, 1996).

The United Nations of Educational, Scientific and Cultural Organization (UNESCO) defines literacy as the ability of a person to function in all the activities in which literacy is required for effective functioning of his/her group and the community and for enabling him/her to continue to use reading, writing and calculation for his/her own and the community's development (EFA Global Monitoring Report, 2005). This is strongly endorsed by Adelore and Olomukoro who view literacy as being very critical for a country's development because it brings empowerment to women which affects their lives (2015).

According to UNESCO Institute for Life Long Learning (2013), worldwide, a total of 774 million adults (aged 15 years and older) are illiterate and two thirds of them (493 million) are women. Illiteracy is a massive problem in Africa. It acutely affects development. This has become quite conspicuous among most rural women, in Morocco, who live in disadvantaged conditions by virtue of lack of livelihood improvement which is systematically caused by illiteracy. One should know that a community with a high rate of illiteracy appears to suffer as a group. This structural fact is profoundly embedded in the population with which the researcher worked in the region of Fes-Meknes.

Women's participation in the Adult Literacy Programs in Morocco is a milestone in achieving sustainable development. In fact, Adult Literacy Programs are initiated with a participatory approach at grass roots levels to enable women to address their own needs.

Moving from law 83.24 to law $112.12^{1}$ has largely rectified and detailed the meaning of cooperatives and their legal procedures. This undoubtedly signifies a great deal of will to improve the quality of life for people in remote and precarious areas. It should be noted that Morocco's recent cooperatives law amendment comes as a result of learning from previous unsuccessful experiences of many cooperatives due to financial, legal, and/or supervisory reasons. This has called for the conceptualization of a national framework in order to alleviate the problems of the rural world by creating more income-generating projects so as to combat poverty, literacy and unemployment. 


\section{Literature Review}

In Morocco, female rural cooperatives have theoretically and empirically undergone a plethora of problems (Brydon \& Chant, 1989). These problems range from training, finance to accompaniment which have consequently led to either project abandonment or failure. Similarly, Morocco constantly strives to fund projects in precarious areas that have a solidarity feature either through Mohammed V Foundation for Solidarity (FMV) and/or the National Initiative for Human Development (INDH). Furthermore, Morocco has paid a considerable amount of attention to rural women in recent years in order to include their participation in local, regional and national development. These efforts have been made to develop, enhance and most importantly systematically regulate this sector. In effect, rural women can, if supported through empowering partnerships, create their own jobs (Saidi, 1993). Empowering partnerships can tremendously help rural women become more productive, assertive and even influential in their community. When women are actively involved in the workforce, they greatly contribute to the nation's progress. As Gates (2019) puts it, "I believe women's groups are essential for each of us individually but also for societybecause progress depends on inclusion, and inclusion begins with women" (pp. 261-262). Thus, women's inclusion in the public life helps everyone prosper, forge ahead with progress and realize their potential. Given this, solidarity cooperatives perform a decisive role in refining women's talents through the appropriate use of their skills for the interest of society. They are prolific spaces where every woman who is trapped in poverty can meet, discuss issues, reorganize and lead.

In recent years, SSE is deemed to be fundamentally core to achieving the principles of justice for social groups, as well as achieving development that guarantees greater interests. This concept began to spread in the 1990s due to the absence of an innovative model, and is currently gaining increasing support as an alternative to the traditional development model, which is based on supporting growth. Furthermore, SSE, whose founding principles are an integral part of the deeply rooted traditions of Moroccan society (collective and solidarity actions), would form an unshakable foundation for reviving local and regional development through novel and genuine initiatives that can gradually fuel growth and ensure well-being. This particular economy type has drawn a lot of attention from international agencies, such as the French Development Agency (AFD) ${ }^{2}$, which agreed to provide a $€ 1.5$ million (MAD 16 million) grant to the Moroccan Ministry of Tourism, Air Transport, Handicrafts and Social Economy, to help consolidate the social and solidarity economy framework in Morocco. In this regard, the repercussions of COVID-19 prompted Morocco to make rapid decisions to support citizens and companies severely affected by the economic recession as the government launched a support program to finance solidarity economy projects by strengthening the role of cooperatives in order to increase development and reduce unemployment.

Defourny (1992) states that necessity is often a condition which prompts the emergence of social economy initiatives. Given the specific social purpose of this type of economy, it naturally tends to attract groups, users or clients who do not have access to employment or certain goods, products and knowledge, or whose access to them is limited. In fact, social and solidarity organizations contribute to creating alternatives to mainstream economy focused on territorial and community development, characterized by collective ownership or management of the means of production, and redistributing surpluses to disadvantaged groups and communities (Utting, 2015). In Africa, for instance, traditional practices that incorporate elements of cooperation, solidarity and collective ownership have existed throughout history to tackle specific social and economic needs (Borzaga \& Galera, 2014). The solidarity economy has brought to public attention notions of social utility and collective interest, and at the same time raised the question of the aim of these activities.

\section{Methodology}

The current study is qualitative in nature. A series of focus groups' sessions were conducted throughout this study in different places in the region of Fes-Meknes, namely Ifrane, Azrou, Imouzzer, Sefrou and Ain Louh. The impetus behind the use of qualitative research analysis is to enable the researcher to contextually investigate and explore the challenges faced by rural female cooperatives in order to be at a better position to make workable recommendations. Such recommendations are meant to mitigate the socio-economic effects of rural female entrepreneurship, alleviate illiteracy rate in rural communities, and simultaneously challenge the status quo.

\subsection{Population}

The research participants were rural women, mostly illiterate, belonging to different age groups between 20 and 46 years old. The overall number of research participants were 20. It was difficult for the researcher to personally meet with the research participants at first due to lack of familiarity with specific places, such as Ain Louh and Imouzzer. However, informal meetings with a few association leaders, in the region, helped pave the way for data collection and meetings with the aforementioned participants were made possible. Prior to collecting data, the researcher kindly asked for participants' consent. The duration of data collection was 3 weeks.

The questions of focus groups revolved around three main categories:

\section{Category 1: Personal information \\ Category 2: Socio-economic ties and administrative procedures \\ Category 3: Challenges}

In addition, the focus groups' main objective sought to come up with a few recommendations with respect to the most prominent challenges that rural women face in their workforce, namely solidarity cooperatives. The majority of questions addressed entrepreneurial pathways, public and private economic networks and partnerships alongside perceptions about cooperatives and the opportunities they provide. The final part was the longest and most important as questions specifically addressed the obstacles that Moroccan rural women encounter in cooperatives, mainly those making traditional carpets and silk buttons.

\section{Data Collection and Classification}

In the section below, the researcher provides a list of the main challenges that most rural female cooperatives, in the region of Fes-Meknes, face. It must be noted that these challenges are entirely banked upon the input and testimonies provided by the research participants, using the hermeneutic approach. One should know that the beating heart of the current research project is the recommendations themselves that were drawn from a genuine environment in order to help rural female cooperatives in the aforementioned region thrive and make their way to local markets and incubation centers.

\subsection{Main Challenges based on the results of focus groups' sessions}

The following challenges were deduced from the focus groups' sessions that were conducted in the region of Fes-Meknes (Please, see appendix A). Almost all research participants shared the same content, with respect to challenges, primarily faced at the administrative and financial levels, because they share the same characteristics, such as illiteracy, precariousness and lack of training and finance.

- Lack of female participation in cooperatives

- Long and expensive legal and administrative procedures

${ }^{2}$ ADF Grants $€ 1.5$ Million to Develop Social, Solidarity Economy in Morocco. By Toms Dumpis. April 2, 2021. 
- Pervasiveness of illiteracy and lack of training

- Lack of means of marketing

- Lack of financial support and banking familiarity

- Lack of partnerships and stakeholders

\section{Recommendations}

In reality, the aforementioned challenges display a threatening loophole in dealing with Moroccan rural cooperatives. These challenges cannot be surmounted unless there is an urgent mobilization of all components of society. Rural female cooperatives should be approached via a novel and concrete mechanism which ensures successful results of women in the job market. Therefore, based on the data collected by dint of focus groups' sessions with women in different cooperatives, the following recommendations have entirely been drawn from the constant problems that female rural cooperatives encounter in the region of Fes-Meknes.

\subsection{Solidary and Associative Work}

Engage young females to join the associative/cooperative work as most women who exist in cooperatives are old housewives with many children and lack enthusiasm in what they do. In fact, the work they generally do does not genuinely serve women's goals toward cultural emancipation, leadership and socio-economic empowerment. The positions they possess in cooperatives are leadership-free, and hence they are very likely to change their livelihood. Given this, there must be a strong recognition among policy makers that rural women are an inseparable constituent in the socio-economic development. This unquestionably requires the will and commitment of private and public sectors to institutionalize, promote, and fortify the rural world in Morocco. This will help valorize their traditional know-how to eventually catalyze not only local economic development, but also serve as cultural ambassadors who would represent Morocco in a plethora of international events (the example of Amina Yabis). Rural women are domain experts when it comes to traditional know-how, such as carpet making, silk buttons, oil essentials, and so forth. Similarly, instilling in the members of cooperatives that teamwork is essential, and that having different opinions is absolutely desirable and negotiable. Dialogue is the key to reaching a comprise to avoid misunderstandings about tasks and finances.

Task division must be a pivotal element in the backbone of cooperatives. Each member should be responsible for a specific task, such as financing, accounting, manufacturing, packaging, marketing, representing, and so on. This will give each member a sense of purpose, responsibility and achievement. It will also be manageable for them to detect and monitor manufacturing problems and track progress Moreover, spreading the culture of collective and solidary work can immensely help rural women build more trust in government institutions as these women fear bureaucracy, especially with regard to administrative procedures that take place farther than their village. One should know that patience and persistence are two key elements in the association/cooperative continuation and success. For a project to blossom, it takes a lot of discipline, hard work, networking and novelty. Rural women should completely grasp that it is perfectly normal for a project's fruits to ripen up to be time-consuming. For this reason, spreading stories of success of female cooperatives via TV shows, newspapers, magazines and newsletters at the national level can be extremely encouraging. A case in point would be the story of Amina Yabis whose main signature product is silk buttons. She has been the center of attention in many national and international organizations. She has also been seen as an iconic figure fighting feminine poverty and helping other women do so in Morocco. With hindsight, female cooperatives should introduce more novelty and creativity to traditional carpet-making, for example, where motifs and colors should be more appealing to respond to customers' needs. One way to do this is to create an electronic catalogue where customers can look through to choose their favorite design and colors, and from there proceed with the purchase. Another way to go about the design, although both energy- and timeconsuming, is to do a needs analysis survey to investigate what generally people, in a certain region, like about traditional carpets. Such a way will help rural women identify customers' needs in order to channel their traditional know-how toward gainful and marketable products.

\subsection{Legal and Administrative}

First and foremost, identifying constant problems that cooperatives encounter in Morocco, especially at the administrative and legal levels (long and expensive bureaucratic procedures) is the springboard. After identifying the aforementioned problems, then one can suggest periodic mobilization of some centers to help rural women do paperwork and other administrative tasks because the farther the place is, the more discouraging it becomes for them. In the same vein, amend the cooperative law, 112.12, and other regulations to include more rural female participation by facilitating administrative procedures. Cooperatives need a regular dialogue with decision-makers. Administrative and financial support, as well as a close end-to-end project accompaniment (pre-creation, creation and post-creation) should be given priority to rural female cooperatives, especially those in remote and precarious areas in order to guarantee the start, continuity and success of their projects. Similarly, include the Nagoya Protocol in the Moroccan cooperative law, 112.12, as the latter guarantees copy rights and protects products and genetic resources against piracy, imitation and forfeiting, as well as ensure legal adaptation of cooperatives to the new law 112.12 that was made in 2014 as many cooperatives are still stuck in the old law 83.24 up to date. Perhaps government agents should do legal follow-ups to cooperatives or at the level of '1'ODCO', and facilitate procedures in order for these cooperatives to be legally founded and regionally acknowledged. In so doing, facilitating legal procedures for cooperatives in order to create their own trade union whose representative will act a medium of communication between members of cooperatives and other government and/or civil society institutions in case of legal modifications. It must be noted that the presence of brokers in cooperatives is problematic as they perpetually take advantage of rural women by buying the products they make with a low price, and then selling them again with a high expense. The result is the net profit ratio for these women is too minimal, which becomes discouraging for them. The solution would be to directly introduce these products to solidary markets, which should be cost free and accessible at all time. In doing so, brokers will have zero benefits, and hence they will incrementally disappear in cooperatives.

In brief, establishing a database observatory and advisory committees, in the whole of Morocco, will enhance the importance of research and data collection to track and evaluate cooperatives' development locally, regionally and nationally. This will ipso facto help facilitate the exchange of experiences among cooperatives in the region in order to unify efforts and promote a sense of solidarity, positive competition and social cohesion.

\subsection{Literacy, Training and Research}

Project accompaniment ought to be provided since the embryonic stage of female cooperatives as the beginning tends to be challenging, shaky and blurry. Viewed this way, launching vocational/professional disciplines at the level of universities will provide and equip students with quality training, skills and know-how of project accompaniment (business plans, project management, marketing, etc.) to eventually become trainers themselves to help rural women with their projects. These students will have the chance to do internships inside cooperatives and work in tandem with their members in order to better understand the nature, philosophy, dynamics and value chain of certain valuable products. Likewise, to orient Moroccan universities to be more citizen-oriented so as to participate in local and regional development, and be an important stakeholder in societal change. This can be done through the creation, implementation and coordination of hands-on training sessions to entice a large participation of students. In addition, civil society, such as INDH and FMV can partially help fund such vocational/professional trainings/disciplines. This will incrementally pave the way for the creation of educational ties between schools and cooperatives where students would visit cooperative sites and be practically introduced to the culture of solidarity economy. Students can also organize workshops and small expositions for rural women's products. A case in point is Al Akhawayn University in Ifrane, which closely works with cooperatives in the region of Ifrane-Azrou. The research participant, in this research project, find this initiative to be truly helpful as they are instructed, acknowledged and presented to academic contexts where they converse and share their ideas and concepts 
with students about what they do in their cooperative, and hence find ways to express themselves in academic settings and commercialize their products.

Likewise, encouraging university students to do rural community projects where the emphasis is put on finding remedy to issues with which rural people struggle can be stimulating and empowering. This will create a platform for students where they will be empirically involved in projects that are of paramount importance to the rural community where all disciplines are called upon for action, such as medicine, agriculture, engineering, architecture, human sciences, and so forth. Such civic community engagement will undoubtedly enable students to turn what they theoretically learn into practice where they can have hands-on experience, which most of the time is entirely invisible in their curriculum. The fruits of these projects can directly be allocated to continuously building a more sustainable and solidary rural community through innovation, dedication and participation of private and public stakeholders. In this regard, encouraging and funding research projects on cooperatives across Morocco will pinpoint and make firm conclusions about cooperatives' failure/success, as well as find workable ways inspired from actual ground to improve the conditions of cooperatives. This will simultaneously enlarge the scope of participation of rural women in Morocco to fight illiteracy, exclusion, and poverty. In addition, the cooperative head should be someone possessing a fair number of soft skills and is certainly familiar with value chain production. This will help much with the manufacturing and marketing processes.

In short, solidarity economy should go hand in hand with sustainable development. Rural women should be mindful of the fact that environment protection is a priority and responsibility.

\subsection{Marketing, E-Marketing and Media}

Offering marketing training courses to cooperative members where the focus is on brainstorming marketable concepts that are vital and important to the region where they live, with reasonable and affordable prices can be the starting point. In the same vein, administrative, artistic and technical workshops are recommended and the language of instruction should be Moroccan Arabic (Darijja), as most of the beneficiaries, rural women, are either illiterate or poorly educated. They can barely speak Classical Arabic, let alone French. In the same manner, digitalizing the work and activities done by cooperatives to create their own webpage, Facebook page, Instagram account, and a personal app to publicize and market their products is strongly recommended. This way rural women can work outside the region they live in and solely mail their products with Amana, FedEX, DHL, or UPS, for example, to their customers across the globe. This way, cooperatives will maximize their profits and take their work to the next level. That is to say, to find foreign markets to which products can be sold. Likewise, encouraging more incubation centers in cities combined with quality training and well-equipped stores where the members of cooperatives have the potentiality and possibility to sell their products will tremendously push rural women to continue working together inside cooperatives. In so doing, beneficiaries will hone their know-how, and at the same time extend their network to target more clients and markets. Incubation centers help cooperatives to be constantly close to their customers, which will effectively and gradually establish customer loyalty. Furthermore, solidary markets are to be enhanced and disseminated across big cities, such as Rabat, Casablanca, Fes, etc. This will give an extraordinary opportunity to cooperatives to sell their products and be known locally and regionally. Finally, fostering and enriching craftsmen with a traditional know-how feature will at least keep them from vanishing though spreading exhibitions and markets in tourist places that encourage the work of craft cooperatives. In other words, it will be tantamount to killing two birds with one stone. In other words, to make visible and expose the cooperatives' products to foreigners and commercialize them at the same time.

\subsection{Banking and Finance}

Cooperatives require a lot of funds; hence banks should be willing to lend money to cooperatives with low interests (3\% or $4 \%$ ). In fact, rural women find it extremely difficult to form a cooperative due to the finances it necessitates, as most of them are household heads; but certainly, not breadwinners. To instill a banking culture in the cooperative members; that is, to have their own bank account for money reception and/or transfer can help them extend their horizon. Besides, periodic visits of 'l'ODCO', INDH, and FMV officials and stakeholders are recommended to monitor, supervise and encourage the work of cooperatives.

\subsection{Partnerships and Stakeholders}

Partnerships continuously require an enhanced collaboration of stakeholders, such as professionals, trainers, facilitators, volunteers, engineers, entrepreneurs and bank directors to better contribute and catalyze national development through solidarity economy and social entrepreneurship. Involving the private sector (universities, companies, banks, etc.) at the regional level can likely strengthen ties between the region's cooperatives.

It must be noted that creating an open space for communication between the various actors in the field of social innovation and solidarity economy will definitely help promote cooperatives, prolong their life expectancy and perpetually fuel and embolden the vital roles they play in sustainable development. Similarly, sensitize young people and the general public by encouraging the creation of new promising areas of activity, particularly non-formal education and vocational training centers. In the end, cooperatives should continuously open up to other civil society actors and engage in multi-stakeholder partnerships to fortify and deepen their impact on development. A case in point would be having a partnership with local hotels where women in cooperatives expose their products to local and foreign tourists.

\section{Conclusion}

This study was an attempt to unveil the main problems that Moroccan female cooperatives face in rural areas in the region of Fes-Meknes. As seen above, the problems are real and embedded in the structure and narrow vision of some cooperatives. Albeit a plethora of regional and national efforts, Moroccan rural cooperatives haven't yet reached maturity according to study results. They are primarily faced with issues that are inextricably linked to project accompaniment, manufacturing and marketing. Providing orientation, guidance and training to female rural cooperatives can and will become a key player in achieving sustainable community development. Therefore, more policies are needed to create a better access to basic social services, including education, health care, insurance and other crucial resources, such as finance and partnerships. Rural women's contribution is tremendously core to the fulfillment of a healthy and prosperous economy. Therefore, more efforts should be made in order to meet a variety of investment needs.

\subsection{Further work}

Future research and studies should investigate the implementation of technology and machinery in rural cooperatives for the purpose of product optimization.

Funding: This study was not funded in any shape or form by any party.

\section{References}

Adelore, O. O., \& Olumokoro, C. O. (2015). Influence of literacy education programmes on socio-economic empowerment of women in Edo and Delta States, Nigeria. US-China Edu. Rev., 5(5): 315-324.

Borzaga, C., \& Galera, G. (2014). The potential of the social economy for local development in Africa: An exploratory report. Policy Department, Directorate General for External/Policies, European Parliament. 
Bruhn, J. (2009). The Group Effect. Boston, MA: Springer US. [Crossref], [Google Scholar]

Brydon, L., \& Chant, S. H. (1989). Women in the Third World: Gender issues in Rural and Urban Areas. Rutgers University Press

Defourny, J. (1992), Histoire et actualité du fait associatif. In Defourny, J., Laloi, N. J., (eds.), Vie associative et fonctions collectives, CIFOP, Charleroi, pp. 21-34.

Defourny, J., \& P. Develtere. (2009). The social economy: The worldwide making of a third sector. In J. Defourny, P. Develtere, B. Fonteneau and M. Nyssens (eds.). The worldwide making of the social economy: Innovations and changes, Leuven: ACCO.

Dobbernack, J. (2014). The politics of social cohesion in Germany, France and the United Kingdom. Hampshire: Palgrave Macmillan.

Dragolov, G., Zsófia, I., Jan, L., Jan, D., Klaus, B., \& Kai, U. (2016). Social cohesion in the western world: What holds societies together: Insights from the social cohesion radar. AG Switzerland: Springer.

Dumpis,T. (April 2, 2021). ADF Grants $€ 1.5$ Million to Develop Social, Solidarity Economy in Morocco. https://www.moroccoworldnews.com/2021/04/338773/adf-grants-e1-5-million-to-develop-social-solidarity-economy-inmorocco/).

Gates, M. (2019). The moment of lift: How empowering women change the world. London: Pan Macmillan.

Gough, I., \& Olofsson, G. (1999). Capitalism and social cohesion: Essays on Exclusion and Integration. London: Palgrave Macmillan.

Hickman, J., Nicola, M., \& Crowley, H. (2012). Migration and social cohesion in the UK. York: Joseph Rowntree Foundation.

Institute for Lifelong Learning (UIL) (2013). Literacy programmes with a focus on women to reduce gender disparities: Case studies from UNESCO effective literacy and numeracy practices database (Litbase). Hamburg: UNESCO/UIL. Retrieved from http:

//www.unesco.org/uil/litbase.

Jenson, J. (2010). Defining and measuring social cohesion. Hampshire: Commonwealth Secretariat.

Larsen, A. (2013). The rise and fall of social cohesion: The construction and de-construction of social trust in the US, UK, Sweden and Denmark. Oxford : OUP.

Lipietz, A. (2001). Pour le tiers secteur. L'économie sociale et solidaire pourquoi et comment. Paris : La documentation française-La Découverte. Loi n 112-12. Bulletin officiel, 2018-08-02, n 6696, pp. 1486-1508. Secrétariat général du gouvernement, Maroc.

Maxwell, J. (1996). Social dimensions of economic growth. Department of Economics, University of Alberta.

Mizukami, T. (2016). Creating social cohesion in an interdependent world: Experiences of Australia and Japan. New York, NY: Palgrave Macmillan.

Reitz, G., Raymond, B., Karen, D., \& Kenneth, D. (2009). Multiculturalism and social cohesion: Potentials and Challenges of Diversity. Toronto : Springer.

Saidi, S. (1993). Genre et économie : La participation des femmes à la vie économique. Féminin-masculin: La marche vers l'égalité au Maroc, 2003, 149-192.

UNESCO. (2005). EFA Monitoring Meeting held in Dakar. Retrieved from http://UNESCO.org

UNESCO. (2013). Literacy Programmes with a focus on women to reduce gender disparities. UNESCO Institute of Life Long Learning. Feldbrunnenstraße 5820148 Hamburg Germany.

Utting, P. (2015). Social and Solidarity Economy beyond the Fringe. United Kingdom, Zed Books.

Vertovec, S. (2003). Conceiving cosmopolitanism: Theory, context and practice. Oxford: Oxford University Press.

\section{Appendix A}

\section{Focus Groups' Questions}

1. Who encouraged you to join the associative or cooperative work?

2. Did members in your community support you?

3. Did you have any training before?

4. Have you previously benefited from any funds or donations from public or private institutions?

5. Have you ever benefited from any previous literacy initiative?

6. How do you think you can improve the quality of the products you are making?

7. What did you learn from this experience so far? 